\title{
Los seguros sociales obligatorios en España
}

\section{Por PABlo de chuRRUCA Plaza}

I Gestión de los Seguros Sociales. Instituto Nacional de Previsión.

II Seguro de Accidentes del Trabajo, que tiene dos partes:

1 a Parte: en la Industria.

2a Parte: en la Agricultura.

III Subsidio de Vejez

IV Seguro de Maternidad.

$\checkmark$ Subsidios Familiares.

VI Seguro de Silicosis.

VII Seguro de Enfermedad.

VIII Unificación de los Seguros Sociales.

\section{INTRODUCCION :}

Noción.-Cuando hablamos de los seguros sociales obligatorios, nos referimos "al conjunto de disposiciones legales de carácter asistencial que, inspirándose más o menos en la institución del seguro privado, han sido dictadas para procurar a los trabajadores económicamente débiles y a sus familias una protección, una seguridad, contra los trastornos que supone la pérdida o la disminución sensible de la capacidad laboral o el aumento en sus necesidades, debido a las vicisitudes de la vida humana". Con esta protección que dan los seguros obligatorios pueden los trabajadores verse libres de lo que muchos llaman el "temor a la necesidad" y puede la colectividad evitar las profundas crisis que producen las situaciones de miseria.

Origen.-Los descubrimientos científicos del siglo XVIII trajeron el maquinismo, la implantación de la gran industria moderna y con ella a la par de grandes empresas con enormes capitales, la formación del proletariado. El jornal era la vida de la nueva clase trabajadora, que venía a 
depender así de las fluctuaciones de la oferta y la demanda. El trabajo era considerado mercancia y por lo tanto había el mayor interés en fijarlo al precio más bajo posible, resuitando el jornal casi siempre insuficiente para satisfacer aún las necesidades más elementales del trabajador. Más, si ceta ers la situación del trabajador efectivo, ccual no sería la dei que, por enfermcdad, vejez, paro o accidente dejaba de obtener ingresos? Como consecuencia de esta inseguridad vinieron graves trastornos sociales que los gobiernos han tratado de evitar, y después de un largo y difícil proce. so de formación ha venido a implantarse el moderno recurso de los seguros sociales obligatorios.

Proceso de fomación.-La traneformación industrial a gue hemos aludido más arriba vino a coincidir con la época de aúge de las doctrinas liberales e individualista. Los gobiernos juzgaron lógico el abstencionismo máe radical y siendo tanta y tan pura la libertad de que disfrutaron las clases trabajadoras, éstas sc vicron apoyadas úacamente por el fruto de su propio trabajo, y quedaron así en la situación económica más payorosa. El Estado comprendiendo el fracaso de cemejantes doctrinas empezó a fomentar la práctica de la previsión en su grado más elernental y sencillo: el whoro. Fero cuando no se tiene suficiente para vivir iquien niensa aun - horar? Tambien se trató de practicar io sistencia imponiendo a la colecrivad la carga de la aterción de los enfernos, inválidos, etc. . pero esto tamroco fué wa solucior.

Liegó a ser tan critica la situacion gue el Entado, por muy convencido que enve lé laisser foire no twvo más remedo que interven irectamenie en las relacione de trabajo y se dienon entonces las prmens leyes protectoras dol trabajador. Eataz vorsabri sobre los diferentes aspectos de la vida en el taller: salubriciad, jornade, descanes, etc... La protección más tarde estudió el riesgo, jue aranazaba la capacidad de irabejo y fué así gue se deó la fórmulo d: la frevisión social en su segundo gredo es decir del seguro. Este consiste en la distribución de las con secuencias económicas de un riesgo entre todos los que se sienten amenarados por a mismo. El seguro fué sugerido al Estado en primer lugar por los propios interesados como una medida eminentemente defensiva, y en segundo lugar por las diferentes instituciones de seguro mercantil, que vie. ron así la manera de ensanchar su esfera de negocios. Estas actuaciones de seguro libre unidas al deber de asistencia que realizaron muchos Estados constituyen la fuente en que se inspiraror los legisladores para la creación del sistema de los seguros sociales. Estos esfuerzos, sin embargo, no tuvieron éxito, pues únicamente podía disfrutar de este seguro el que reciprocamente ofrecía también y como el caso era el de ayudar precisamente al que no tenía, lo gran masa se vió privada del goce de la institución del "seguro social libre y subsidiario por el Estado".

La obligación.- Mientras que en Inglaterra se favorecía el seguro libre y subsidiario por el Estado, en Alemania y en los países del centro de Europa se imponía por la ley a los individuos la obligación de ser previsores por estimar que así lo exigía el interés social. Este sistema produjo los mejores resultados ya que los seguros sociales o son obligatorios o no son nada, y es el sistema obligatorio el que ha venido a prevalecer. La obligación de la previsión no es una fuerza contra la libertad humana, es únicamente una coacción que mantiene en su justo límite a la voluntad, 
evitando así que salga del orden moral, sin el que el hombre no puede cumplir con su misión providencial en el mundo.

Principales etapas de este proceso:

Año 1883.- Alemania implanta el primer seguro social obligatorio: el de enfermedad." Bismarck quiso asi suprimir las causas de descontento entre las clases trabajadoras y ligar el proletariado al Estado.

El fundamento del seguro social obligatorio, dicen los alemanes, está en la teoría del riesgo profesional y en la necesidad de garantizar a los económicamente débiles un mínimo de nivel de vida.

Año 1911.-Inglaterra impulsa vigorosamente el nuevo principio de la obligatoriedad con la promulgación del National Insurance Bill, haciendo forzoso para los trabajadores los seguros de enfermedad, invalidez y paro. Lloy George es el político inglés que dá este gran paso, infundiendo nueva vida al partido liberal, y presentando su obra a la opinión pública como una prima contra la revolución.

Año 1919. - Con la terminación de la guerra el seguro social adquiere una extraordinaria difusión en el mundo. Es a partir de esta fecha que se comprende claramente la noción del deber social del Estado, y es la Oficina Internacional del Trabajo, el organismo que se encarga de cum-
plir con él.

La evolución er España.-España, como todos los pueblos más o menos industrializados del mundo, ha reaccionado también contra el indi. vidualismo liberal del siglo XIX. Puede decirse que fué en el año 1883 que empezó España a trabajar en la política de protección al trabajador, por medio de la "Comisión de reformas para el mejoramiento de la clase obrera". Entre los temas de estudio figuraban los que hacían referencia a los accidentes, enfermedades profesionales y a la vejez de los obreros. El seguro social penetra en nuestra legislación con la ley de Accidentes deí Trabajo de 30 de Enero de 1900; se basa en el principio del riesgo profesional.

Año 1908.-Creación del Instituto Nacional de Previsión, por ley de 27 de Febrero de 1908, cuya misión en un principio se refirió a las pensiones de retiro y más tarde abarcó todos los seguros de utilidad pública de personas.

Año 1919.- Se implanta el seguro social obligatorio en España con el régimen de "intensificación de retiros obreros", reconocimiento de una pensión de retiro para los trabajadores asalariados de la industria, co. mercio y agricultura desde los sesenta y cinco años.

Año 1938.-Promulgación del Fuero del Trabajo. Documento fundamental que resume todo el programa social del Movimiento: reacción contra el capitalismo liberal y el materialismo marxista y renovación católica, de justicia social y alto sentido humano. Anuncia la implantación del subsidio familiar, el incremento de los seguros sociales de vejez, invalidez, maternidad, accidentes del trabajo, enfermedades profesionales, tuberculosis y paro forzoso y refleja la tendencia al seguro total.

Desde este momento tiene el pueblo español trazado su programa en lo relativo al seguro social obligatorio.

En cuanto al fin político del seguro social, decimos que no tiene otro que el de "dignificar el trabajo", dando a quienes lo prestan el dere- 
cho de ser amparados en su infortunio, como compensación al carácter de función política y de servicio al Estado que el trabajo tiene.

Seguros sociales, seguros privados y asistencia.-Conviene hacer una distinción entre estas clases de seguros. El seguro social tiene un contacto evidente con el privado en cuanto que ha recogido de este su contextura técnica (estadísticas, cálculos, tarifas, ecuación entre ingresos y gastos), pero difiere con él, en cambio, porque el primero pertenece a la rama de derecho público y el segundo al derecho privado. El seguro social es obligatorio y tiene por objeto proteger a las masas económicamente débiles, generalmente asalariadas, de los riesgos de orden fisiológico y económico que pudieran sufrir. Tiene pues un carácter amplio, no considera al individuo como en el seguro privado, como unidad, sino en conjunto.

En el seguro social los beneficiarios no son los únicos que contribuyen con sus recursos, son también los Poderes Públcos los que, guíados por su deber de asistencia, respaldan y garantizan estos seguros. Al seguro privado le encontramos un carácter marcadamente mutualista; el individuo aporta sus recursos propios y a cambio de ellos obtiene la protección deseada. En los seguros sociales los beneficios son fijados previamente por la ley, no admiten alteración y son uniformes para todos los asegurados. Por último en el seguro privado hay un fin lucrativo que no existe en el Seguro social obligatorio.

En cuanto a las relaciones entre el seguro social y la asistencia, afirmamos que marchan juntos en cuanto que ambos se proponen luchar contra la falta de seguridad económica en el medio social, pero difieren en lo referente a su modo de aplicación. El seguro trata de evitar que las situaciones peligrosas lleguen a causar perjuicios, mientras que la asistencia busca la forma de aliviar el daño ya producido. El seguro es exigible por todo asegurado, tiene una base jurídica; en cambio la asistencia está basada en un deber de humanidad, pero no puede ser exigida jurídicamente. En los seguros los recursos económicos proceden en general de los asegurados, aunque también del aporte de patronos y del Estado. En cambio la asistencia está basada económicamente en el aporte generoso de particulares y del apoyo que el Estado quiera darle.

Riesgos.-Pero cen que consiste este peligro, del que hemos hablado ya varias veces, que perturba y amenaza al orden social, que es causa de tanta miseria? Pues bien este peligro es lo que se califica corrientemente con el nombre de riesgo. Algunos sostienen que no hay más que un sólo riesgo, el que supone la pérdida del salario. Pero si bien la consecuencia última es ésta, los legisladores han determinado que son sin embargo muchas las causas que la determinan, y son tantas y tan distintas que se ha resuelto considerarlas individualmente como riesgos especiales con sus seguros respectivos que han sido calificadas de la siguiente manera: te del trabajo.

a) De crden patológico: la enfermedad, la invalidez, y el accidenla muerte.

b) De origen principalmente biológico: la maternidad, la vejez y

c) De origen económico social: el paro forzoso y las excesivas cargas de familia. 
Calificamos entonces al riesgo en la doctrina del seguro como un acontecimiento futuro $\mathrm{y}$ posible, ajeno a la voluntad del individuo que si se verifica ccasiona un daño.

Campo de aplicación: Ha sido materia de discusión el determinar a quienes correspondía el beneficio del seguro. Unos decían que éste debía corresponder únicamente a las clases económicamente débiles y asalariadas; otros que si bien era justo que los pobres debían disfrutar de este beneficio, no' veían porqué debían ser estos limitados a los asalariados, ya que hay siempre un gran número de trabajadores independientes, artesanos, etc...que pueden pasar también por momentos difíciles y que merecen apoyo. Este segundo criterio es el que impera, pues ya se ha abandonado la idea primitiva de proletización de las masas, y se procede en cambio con un criterio más amplio y humano, teniendo constantemente en vista el bien general de la colectividad.

Así cuando el patrono tiene a su cargo a un número determinado de trabajadores, tendrá la obligación de incluirlos en el seguro, siendo responsable en el caso de no hacerlo. Si el trabajador es independiente, deberá éste proceder a afiliarse por su propia cuenta, de lo contrario no podrá disfrutar de las consiguientes ventajas.

Se da el nombre de prestación al beneficio que obtiene el asegurado en el caso de que se materialice el riesgo. Esta prestación es normalmente inferior al daño sufrido, y puede prestarse tanto en metálico como en especie. También es característico de la prestación hoy en día que no se limita únicamente a satisfacer el daño en la persona que lo sufrió, sino que tiende a proteger al círculo familiar. Su objeto es no sólo indemnizar sino más bien prevenir.

En cuanto a la Administración: Hay cada día una mayor tendencia a la unificación en las instituciones de seguros sociales, con el objeto de disminuir los gastos. Asimismo se van eliminando las empresas aseguradoras que no tienen origen oficial.

Visto así el contenido del seguro social, estudiado su origen y proceso de formación entramos al estudio más detenido del seguro social obligatorio en España. Estudiaremos separadamente cada seguro, exponiendo en cada caso el alcance del riesgo, sus fuentes legales, etc...

\section{CAPITULO I}

\section{GESTION DE LOS SEGUROS SOCIALES INSTITUTO NACIONAL DE PREVISION}

El primer paso dado en España en favor de la polítza social de previsión data de 1908, con la creación del Intituto Nacional de Previsión, que es una institución autónoma, creada por el Estado para regir todos los servicios intervencionistas en materia de seguros sociales $y$ difundir $e$ in- 
culcar la previsión popular. Es pues una institución de orden público, con ceracter antónomo $y$ que no persigue on su labor ningún fin lucrativo.

Posteriormente, diversas leyes han ido pexfeccionando su estruciu. ra. En 1938 se le endaza con el Fuero del Trabajo, en 1939 se modifica su organización local y en 1942 se dispone que la Fresidencia de la Comisión Permanente dé Irotituo la ejerza fl Ministo del Traboio.

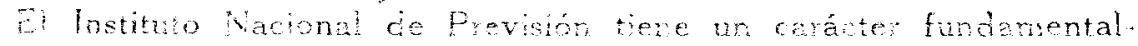
mente autonomo: poree personal propio curas condiciones de ingreso, sueldo. sereacism. petmo, etc. . regula por á momo; sus ingresos princi. pales ro fruran en los presupuestos nacionales, no proceden de los impuestos.

Sin embarco el Estado tiene una participación constante en la gestión, que ejcree por medio del Presidente de la Comisión permanente del Instituto. Se comprueba asi el Balance técnico de las operaciones del Ins. tituto, se producen los nombramientos $y$ en una palabra se controla al Instituto de manera que no proceda en forma contraria a los intereses de la Nación.

El Instituto tiene una triple función:

a) Gestión administrativa y sus garantías. La gestión administrativa se viene rdalizando de dos maneras: como función y como servicio. Como función actuando directamente con los propios órganos de la Institución; como servicio, esto es, en régimen de completa autonomía dentro del mismo Instituto.

El Instituto ofrece una serie de garantías que son de orden técnico, puramente administrativo, y de orden financiero.

Inversiones: el Instituto distingue dos clases: financieras y sociales. Las primeras deben hacerse buscando colocaciones tranquilas que aseguren, hasta donde sea posible, una renta moderada y sostenida. Con las segundas, sin olvidar nunca la solidez de la inversión, se busca además el atender a alguna necesidad social. Se entiende que estos fondog que se invierten no son los que se necesitan para la atención de necesidades inmediatas, pues estos deberán permanecer en Caja. En cuanto al rendimiento de estas inversiones se ha establecido un mínimo de $31 / 2$ por ciento.

b) Gestión difusora. Le corresponde al Instituto ir formando opi.nión en torno a su obra. Esta labor de difusión la ha venido realizando el Instituto por medio de numerosas conferencias, discursos, publicaciones, etc.

c) Gestión de asesoramiento. Con su función asesora el Instituto estudia y prepara los proyectos de reforma en todo lo refsrente a seguros sociales, siempre que el Estado solicite esta cooperación.

\section{Organización.}

El Instituto consta de órganos centrales y locales. Los centrales radican en Madrid y son: el Consejo. el Presidente, la Comisión permanente del Consejo, el Comisario y el Subcomisario.

Los órganos locales son indispensables en nuestro sistema español, porque nuestros seguros no están organizados sobre base profesional, al. canzan a masas económicamente débiles, independientemente de la clase de trabajo que realizan. For esto e! Instituto ha tenido que adaptar su or ganización a circunseripciones territoriales. 


\section{Los recursos:}

Los recursos de que dispone el Instituto proceden de tres fuentes: los asegurados, sus patronos y el Estado.

De los asegurados y sus patronos proceden las cuotas para la sub. vención de los seguros de maternidad, enfermedad y subsidio familiar.

Del patrono únicamente, cuando se trata de los seguros de accidentes del trabajo y del subsidio de vejez.

Estas dos fuentes de ingreso son evidentemente las de mayor importancia para el Instituto.

Del Estado ha recibido el Instituto como capital fundacional la suma de $500 \mathrm{mil}$ pesetas, y recibe anualmente una subvención proporcionada a su desarrollo y necesidades.

\section{CAPITULO II}

\section{ACCIDENTES DEL TRABAJO: EN LA INDUSTRIA}

\section{A) Objeto y Fuentes:}

Toda actividad laboral lleva consigo un cierto riesgo, riesgo que no llegó a causar verdadera preocupación hasta que se produjo el adelanto industrial del siglo pasado. Los accidentes comenzaron a multiplicarse, los obreros resultaban incapacitados para el trabajo, no había entonces jornal y ellos y sus familias se veían en la miseria. Estaba comprobado que los accidentes eran consecuencia del trabajo y que por tanto debía ser la misma industria la que soportara los gastos que ellos ocasionaran. Sin embargo no fué hasta el último tercio del siglo pasado que el Estado logró vencer las dificultades que la industria ofrecía en cuanto a la carga de estos gastos. la doctrina del riesgo profesional fué aceptada primero en Alemania y Suiza, pero después de haber pasado por las siguientes fases:

Doctrina de la Culpa.-Consecuencia del principio de derecho de que nadie es responsable del daño causado a tercero si no ha incurrido en culpa o negligencia. Según esta teoría si el obrero accidentado no probaba que el daño que había sufrido era debido a defectos en las instalaciones, mala vigilancia, etc... el patrono no era responsable. Fueron naturalmente muy pocos los que pudieron sacar ventaja de esta doctrina.

Doctrina de la responsabilidad contractual-Como consecuencia del contrato de arrendamiento de servicios el patrono se obliga a abonar los salarios convenidos a sus obreros y a vigilar por la seguridad y buenas condiciones del trabajo. Desde este momento se invierte la prueba y cuando se produce un accidente es el patrono el que debe probar que el daño no ha provenido de falta de seguridad. Queda libre de responsabilidad si prueba cue ha habido fuerza mayor, caso fortuito o falta del obrero. Con este sistema el obrero encuentra más protección, pero no toda la deseada. 
Doctrina del Riesgo profesional.-El daño causado por un objeto debe ser reparado por el dueño de ese objeto. (teoría de la responsabilidad objetiva). Basta con que el demandante pruebe la relaciór de causa a écto entre el objeto y el daño para que pueda exigir reparación. Por tanto el que crea una industria o explotación en la que emplea operarios corro elementos de trabajo, sabe que cualquier daño que estos sufran debelá se. cargado a los gastos de la industria o explotación. Esta es la teoría mós justa $y$ la que co modernamente aceptada.

Recorocido, pues, el derecho del obrero a percibir indemnización en caso de acciderte es también necesario garantizarle el cobro de la reparación que mercre; de aqui puede decirse que lo esencial en las leyes de accidentes del trabajo. lo que las distingue unas de otras es on sistena de garantia cortra a posible insolvencia patronal que imposibititaría la in. demnización. Ninguna garantía más eficaz que la de un seguro. Cuando se habla ples de eguros de accidentes del raboio ae alude a aquella serie de medidas cue tienen por objeto garantizar a los trabajadores el pago de las reparaciones que la ley impone a los patronos cuando aqueilos experimentan algun daño en el ejercicio de su actividad profesionai.

Sistcrmas de garantias.-Seguro voluntario y seguro obligatorio.

En el seguro voluntario no es indispensable que el patrono se asegure contra el riesgo de tene: que pagar una indemnización. Lste seguro puede eer de dos ciases: a) sin fondo especia! de garantía (como la legislación inglesa y la española de 1900).

b) Con fondo especia! de garantía (como la legislación francesa y la española después de la reforma de 1922).

En el seguro obligatorio el patrono está obligado a asegurar a su personal contra el riesgo de accidente.

Puede ser también de diferentes clases:

a) Con libre elección por el patrono del órgano asegurador (como la legislación española y la italiana anterior a 1935 ).

b) Con obligación de asegurar on organismo determinado (como la legislación alemana e italiana de 1935).

c) De seguro obligacorio en una institución centralizada (Suiza).

El régimen de garantías vigente en España, después de la reforma de 1932, encaja en el grupo de los paises de seguro voluntaric para las obligaciones sanitarias y de auxilio económico en las incapacidacies temporales. En el grupo de los páses de seguro oblifatorio con libre elección de órgano asegurador, para las obligacionea establecidas en los casos de incapacidad permanente o muerte.

Legislación española: La ley del 30 de Enero 1900 que introducía en España la doctrina del riesco profesional: en caso de accidente, el patrono debía indemnizar al obrero, pero su solvencia económica no of ecía garan. tías y asi muchas veces no podí reparar al obrea el daño sufrido. Esta ley fué reformada por la del 10 de Enero de 1922 que impnso al pationo la oblicación de crear un Fondo de Garantia. En 1928 España ratificó el Conveno inemacional de Ginebra del año 25.

En los años 31 y 32 se reglamentan los accidentes del trabajo en la agricultura y la industria; son las leyes aprobadas cntonces que están actualmente ei vigencia con muy ligeros cambios. 


\section{B) Campos de aplicación:}

La legislación española de accidentes del trabajo abarca un campo de aplicación muy extenso, siendo por tanto grande su eficacia como medida de protección de los trabajadores. La ley es la que indica quienes serán considerados trabajadores, quienes patronos y qué trabajos dan origen a la responsabilidad patronal.

¿Quien es operario? Según el art. $3^{\circ}$ de la ley, "todo el que ejecuta habitualmente un trabajo manual fuera de su domicilio, por cuenta ajena, mediante remuneración o sin ella, aunque se trate de aprendices, ya esté a jornal, ya a destajo, ya a cualquier otra forma, o en virtud del contrato verbal o escrito". En cuanto a los extrangeros, éstos, de acuerdo con el Convenio internacional ratificado por España en 1931, recibixán el mismo trato que los nacionales en materia de legislación de accidertes.

El servicio doméstico es una excepción a la legislación de accidentes. Sin embargo ni los porteros ni los choferes estarán incluidos en esta. clase de servicio, por ser su trabajo de tipo manual exclusivamente.

¿Quien es patrono? El art. $2^{\circ}$ de la ley dice: se considera patrono al particular o compañía, persona natural o jurídica, propietario de la obra, explotación e industria donde el trabajo se preste. El concepto de responsabilidad subsidiaria se admite sólo cuando se trata de obra contratada, cuando existe un contrato de obra.

Están equiparados a los patronos definidos en la ley: el Estado, las Diputaciones provinciales, los Cabildos insulares, los Ayuntamientos y las Mancomunidades de Corporaciones locales, incluso en las obras públicas que ejecuten por administración.

\section{Inidustrias y trabajos que dan lugar a responsabilidad patronal.}

La ley enumera en su artículo 7 las industrias y trabajos que estarán sujetos a responsabilidad patronal, más al hacerlo así no procede con un criterio limitativo sino más bien demostrativo, pues podrán presentarse una serie de casos no emunerados expresamente en el art. 7 que sin embargo den lugar a reparación.

\section{C) Riesgo Cubierto:}

La reparación de accidentes de trabajo tiene por objeto indemnizar a los operarios que hayan sido victimados.

Pero ¿qué se considerará accidente de trabajo? La legislación española dice: "es toda lesión corporal que el operario sufra con ocasión y por consecuencia del trabajo que ejecute por cuenta ajena".

¿Qué es lesión corporal? La legislación española no se explica claramente sobre este punto, pues, dice que es todo daño sufrido ccin ocasión y por consecuencia del trabajo. Por tanto cinterpretaremos esta disposición en ei sentido de que tanto el accidente propiamente dicho como la enfermedad profesional constituyen lesiones corporales? Los legisladores y la jurisprudencia han procedido con diferente criterio. Los primeros no han querido aparejar el accidente con la enfermedad y por ello han dictado leyes in. 
dependientes para ambos. Los segundos en cambio han opinado en el sen. tido de gue la eviermedad profesionai es una consecuencia directa de la labor profesional $y$ por tanto debe er considerada como una lesiór conpo.

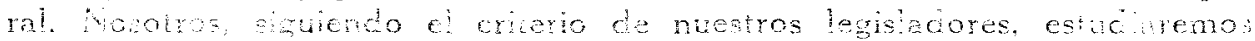
tambing indenendientemente $\epsilon$ l accidente del trabajo $y$ la enfermedad profesional.

Acharion: esta diferencia de opinión a que hemos hecho reb. rencia, entre la loy y la jurisprudercia se debe a que ia ley no habla para nada de lejonco de "acciones violentas y súbitas", con lo que es revto que el concetto comun de lesión (como sinonimo de violencia ejercisa por ur cusre exierior) podría ser aparejado al de enfermedad profesional (con su idea de proceso lento de destrucción).

Lo fundamental en el porqué de la indemnización en los ancien tes de trabajo está en la relación de causa a efecto que deberá existir entre el trabajo que realice el operario que se halla al servicio de un patrono y el daño que sufra como consecuencia de él. Basta pues deriostrar esía cau. salidad para que se convierta en realidad exigible la indemnización. Son considerados así accidentes del trabajo tanto los ocurridos en el taller como los sobrevénidos en momentos en que el obrero se trasladaba al taller para comenzar el trabajo, o cuando iba a cumplir una misión por encargo del patrono.

\section{Fuerza Mayor.}

Cuando hay fuerza mayor extraña al trabajo en que se produce el accidente, no funciona la teoría de la causalidad, pues no existe la relación necesaria de causa a efecto. Sin embargo es muy difícil establecer cuando hay fuerza mayor, pues el caso fortuito presenta características muy semejantes y $\sin$ embargo no destruye el nexo causal.

El Reglamento no considera debidos a fuerza mayor extraha al trabajo los accidentes que reconozcan por causa el rayo, la insolación u otros fenómenos análogos de la Naturaleza. (art. 6).

\section{Falta del obrero.}

La teoría del Riesgo Profesional no cubre aquellos casos en que ha mediado dolo o falta grave del obrero. Así, si el obrero sufrió daños por desobedecer órdenes del patrono, por riña con otro obrero, por juego, embriaguez, etc... el patrono no será responsable. Sí lo será en cambio, si el accidente se produjo por imprudencia profesional, ya que el accidente derivó de la excesiva confianza con que el operario obró, consecuencia de la habitualidad en el trabajo.

\section{Falta del patrono.}

Serán responsables cuardo no empieen todas las medidas posibles de seguridad e higiene del trabajo en beneficio de sus obreros. Se les po. A rá exigir también responsabilidad civil o criminal por los daños y perjuicios ocasionados. Existe un catálogo de medidas generales de indispensable adopción que señala las obïgaciones de seguridad del patrono. 


\section{D) Prestaciones:}

Comprenden: Asistencia Sanitaria e Indemnizaciones.

La Asistencia Sanitaria, lo mismo que las indemnizaciones, tiene carácter obligatorio. Los beneficiarios no pueden renunciar a ella, y cualquier pacto que hicieran sobre este punto, será nulo. (art. 61 de la ley de acciderites).

Primeros Auxilios: constituyen una de las obligaciones patronales más inmediatas, acudiendo desde el primer momento a reclamar los auxilios sanitarios necesarios (arts $25 \mathrm{~L}$, y $52,53 \mathrm{R}$ ).

Dirección Facultativa: Pasado el momento de los primeros auxilios, el patrono estará obligado a designar al facultativo y deberá correr con los gastos que esta asistencia sanitaria ocasione. Si el obrero tiene interés en que lo atienda un médico especial, podrá designarlo, pero él correrá con los gastos. En caso de que haya diferencia de opiniones entre el médico designado por el patrono y el del obrero, se acudirá a un médico de la Beneficiencia Municipal, cuyo dictámen por escrito servirá de prueba en caso de haberse suscitado contienda (arts. 53, 60 y $61 \mathrm{R}$ ).

La asistencia de un médico de la Beneficencia puede ser solicitada en general por el patrono o por el obrero en cualquier caso de accidente $(57 \mathrm{R})$. La designación de facultativo deberá hacerse de acuerdo con el Reglamento (art. 54) ante la Delegación del Trabajo o Alcaldia. Si el obrero se negara a someterse al facultativo que se le hubiere designado, él mismo deberá costearse la asistencia médica.

Hospitalización: En caso de que sea necesario el ingreso al Hospital, el patrono correrá también con el importe de los alimentos, medicinas, honorarios médicos y demás dispendios (arts 55 y $56 \mathrm{R}$ ).

Medicamentos: El patrono deberá costear los gastos de medicamentos que el obrero o su familia podrán recoger siempre que presenten la receta firmada o visada por el médico del patrono (arts. 74, 75 y $76 \mathrm{R}$ ).

Duración de la Asistencia Sanitaria: Durará hasta que el obrero pueda regresar al trabajo o hasta que por dictámen médico sea declarado en el correspondiente grado de incapacidad (art. 25, L). Sin embargo, la jurisprudencia declara que el límite de tiempo para la Asistencia será de un año. Si hay incapacidad declarada se procederá a formar el capital correspondiente.

Dictámen médico: Los arts. 63 y 64, R. establecen la obligatoriedad del certificado médico que dará de alta al obrero o lo declarará incapacitado.

Si el obrero no está conforme podrá pedir nuevo exámen y si éste tampoco lo favorece podrá apelar hasta la Academia de Medicina.

La intervención quirúrgica también está incluida en la Asistencia Sanitaria y será también de incumbencia del patrono.

Indemnizaciones: Constituyen la ayuda económica que el patrono deberá otorgar al obrero que há sufrido un accidente en su trabajo. Al comienzo de este estudio hemos explicado el porqué de este deber. El obrero u operario que trabaja en una industria está sujeto a un riesgo determinado, lo mismo que las máquinas o ustensilios de trabaio sufren deterioros o des. gaste; tanto unos como otros son factores esenciales en la producción y por 
tanto es natural reconocer que los gastos que ambos ocasionen deberán ser cargados a los gastos generales de producción de la empresa.

La base de esta indemnización está en el salario que recibía el obrero en el momento del accidente. Al aplicar este precepto se observarán las reglas de! art. 37 del Reglamento En ningún caso podrá fijarse un salario inferior a dos pesetas diarias.

Indemnizaciones por incapăcidad: La incapacidad implica una pérdida de condiciones para el trabajo, pérdida que admite graduaciones. Hay incapacidad tomporal $e$ incrpacidad permanente según nuestra legislación. La incapacidad temporal es la que implica una lesión que está curada dentro de un término máximo de un año. Para mayor claridad en la clasificación de las incapacidades, exponemos a continuación sus tipos en forma de cuadro sinóptico:

INCAEACIDAD:

Temporal

$$
\begin{aligned}
& \text { Relativa }\left\{\begin{array}{l}
\text { Parcial } \\
\text { rotal }
\end{array}\right. \\
& \text { Permanorte }
\end{aligned}
$$

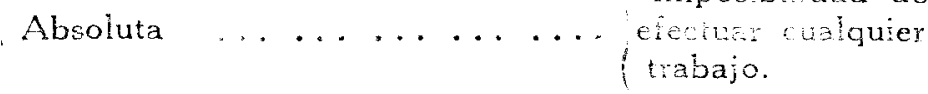

En cuanto al modo de determinación de la incapacidad (sobre todo la permanerte) ha habiclo dos criterios: El uno decía que debía valorarse la incapacidad desde el punto de vista de la pérdida de la capacidad laboral, atendiendo pues a la profesión o trabajo del obrero. El segundo criterio sostenía que la incapacidad se debía determinar por el perjuicio físico experimentedo, sin preocuparse del sendimiento atenuado. La ley sostenía el primer criterio y e! Reglamento el segundo. Fué sclamente en 1932 que triunfó con la Reforma, el criterio de la valoxación de la incapacidad atendiento al trabajo. El Reglamento en su art. 13 fija una serie de situaciones típicas de incapacidad permanente. de hernias, etc.

a Parcial: de la visión complete de m ojo de dedos, aparición

b) Total: pérdida de la maro, de la totalidad de los dedos, de alguna de las extremidades, sordere absoluta, etc...

Cuedro de valoraciones: Cuando no se pudiera establecer concreta y específamente la lesión o lesiones, ni su relación con la pérdida de la capacidad labora: $\epsilon$ art. 25 del Reglamento establece un procedimiento supletorio que consiste en ur cuadro que atribuye un porcentaje especial a cada tipo de lesón. Cuardo la sums de los porcentajes correspondientes a las lesiones sufridas es mayor del 50 por ciento se decharara la incapacidad permanente relativa Cuando se trate do mujeres o de hombres mayores de 60 año, bentaré con el 40 por ciento.

El art. 15 del Reglamento estabiece cuando habrá incapacidad permanente abocua. Fera dar una idea de este artículo reproduciremos someramente aigunas de sus disposiciones: 
a) Pérdida de dos extremidades.

b) Pérdida de movimiento, análoga a la mutilación de extremidades.

c) Pérdida de los dos ojos.

d) Lesiones orgánicas y funcionales del cerebro, corazón, aparato, digestivo etc. .

Las hernias son también estudiadas detalladamente en los arts. 17, 18 y $19 \mathrm{R}$.

El obrero deberá ser examinado médicamente antes de ser admitido al trabajo (art. 20 y $21 \mathrm{R}$ ). Cuando el patrono no tomara esta precaución se presumirá juris tantum, la sanidad del obrero (arts. 20 y $22 \mathrm{R}$ ).

Forma y cuantía de las indemnizaciones: Hay dos formas reconocidas universalmente:

a) Entrega de un capital.

b) Entrega de una cantidad periódica. Renta permanente; auxilio económico temporal.

Nuestro Código acepta cualquiera de estas formas de indemnización.

Revisión: La legislación española prevee también aquellos casos en que pueda variar la situación de un accidentado; en este caso se podrá proceder a la revisión de la incapacidad y por tanto de la indemnización. Esto funciona únicamente en los casos de incapacidad permanente.

'nidemnización en caso de muerte: El art. 28 de la Ley fija la suma de dinero que deberá asignarse a los gastos de sepelio, tomando en cuenta para ello la población del lugar en que éste deba efectuarse.

Indemnización a los derechohabientes: Es el art. 29 del Reglameto que señala los derechohabientes, atribuyéndoles un derecho personalísimo, que no tendrá carácter hereditario, pues ha sido creada esta indemnización por razones de orden social y benéfico.

El Reglamento también estipula qué proporción del salario que recibía el muerto, deberá ser entregado como indemnización a los derechohabientes, indicando también como deberá distribuirse.

\section{E) Garantías :}

El sistema que se emplea en España, como dijimos antes, es el del seguro obligatorio con libre elección del órgano asegurador para los riesgos de incapacidad permanente y muerte por accidentes del trabajo, y el del seguro voluntario para los riesgos de incapacidad temporal y demás obligaciones que la ley imponga a los patronos.

\section{Organización del seguro obligatorio.}

Todos los operarios comprendidos en la ley se considerarán de derecho asegurados contra el riesgo de incapacidad permanente o muerte producida por el trabajo. Los patronos tendrán la obligación de pagar y asegurar. Si nó lo cumpliera, el asegurado no sufre por ello periuicio.

Recursos: las primas o cuotas del seguro de accidente corren a cargo exclusivo del patrono (art. 104 R). Ese gásto está cifrado en una tarifa de primas o cuotas aprobada en 1933 por el Gobierno. La tarifa de primas 
vigente es la que opera la Caja Nacional de Seguros de Accidentes. Ninguna entidad podría operar con tarifas inferiores.

\section{Deberes patronales:}

10 Mostrar en lugar visible del taller el nombre de la entidad con la que ha contratado el seguro.

$2^{\circ}$ Participar a la Inspección el nombre de la entidad aseguradora.

39 Llevar un libro de matrícula y otro de pago de salarios o haberes, en los que estarán anotados todos los datos de los operarios que trabajan con ellos. Estos libros deberán ser presentados siempre que los reclamen los Inspectores del trabajo.

\section{Elección del órgano asegurador:}

Cuando la empreea o industria fuera privada, el patrono podrá asegurar a sus operarios en la Caja Nacional de Seguro de Accidentes del Trabajo, en una Mutualidad patrona! o en cualquier sociedad de seguros.

Pero si se tratara de aseguar a! personal de dependientes de los Ministerion, Coporaciones publica y covnos gue de elas dependan, el securo deberá efectuarse forzesmento on la Caja Necional (arts. 90 y 9 ! P). Decreto del 18 de Junio de 1042. Fi Capitulo X del Regiamento de Accidentes del Trabajo esta in arate dedicudo a regular la aplicación de cens segriros.

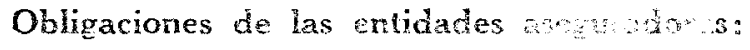

Las Mutueldades Patrondes y las Sociededes de Seguros deberán prestar fiarza en la Caja General de Depósitos o en el Banco de España. Esta fianza en ninzún caso será inferior a 5 mi ptas. y será fijada por las declaraciones que las Musualid fes o Sociededes de Seguros presenten enualmente sobre los salarios asegurados en el año anterior.

Mutulidades: Son aquellas asociaciones que, legalmente constituidas, dedican sus operaciones a reparir entre los asociados el equivalente de los riesgros sufridos por une parte de ellos, sin que puedan estas asociacio. nes dar lugrar a beneficios de ninguna clase. Pueden comprender industrias $y$ trabajos de distintas clases. Deberán asegurar por lo menos a mil obreros y comprender más de diez patronos, salvo casos muy especiales.

Tendrán sus propios estatutos que deberán ser sometidos al $\mathrm{Mi}$ nisterio del Trabajo.

El capital de las Mutualidades deberá aplicarse exclusivamente al objeto social. Deberán remitir anualmente a! Ministerio del Trabajo y a la Caja Nacional, sus Memorias y Balances.

\section{Compañias de Seguros:}

Los patronos podrán contratar directamente con aquellas compañías de seguros que tengan la autorización del Ministerio del Trabajo y que reunan por lo tanto los requisitos que éste les señale:

a) Separación de las operaciones de seguros de accidente del trabajo de cualquiera otra que realicen. 
b) Fianzas especiales determinadas.

c) Aceptación de los preceptos legales en la materia. ces, etc.

d) Comunicación al Ministerio del Trabajo de los Estatutos, Balan-

Así pues una sociedad de seguros no podrá funcionar sin ser aprobada por la Dirección General de Seguros y sin estar inscrita en el Registro del Ministerio del Trabajo.

\section{Reaseguro:}

Tanto las Mutualidades como las Compañías de Seguros deberán reasegurarse por lo menos en un $10 \%$ de la cartera global de riesgos de accidentes del trabajo en el "Servicio de Reaseguro de Accidentes", con el objeto de garantizar aún más el exacto cumplimiento de sus obligaciones.

\section{Caja Nacional de Seguro de Accidentes del Trabajo del Instituto Nacional de Previsión:}

Es un servicio autónomo constituído dentro del Instituto Nacional de Previsión, con capacidad juridica propia para cuanto se relacione con sus fines propios, y sometida a la fiscalización constante del Ministerio del Trabajo. Tiene sus propios estatutos, que fijan sus fines, entre los cuales señalamos algunos:

a) Fijación de las tarifas para el seguro de indemnizaciones por accidentes del trabajo en la industria, que produzcan incapacidad permanente o muerte. trabajo.

b) Seguro directo de todos los riesgos derivados de accidentes del

c) Pago de las rentas de indemnización.

d) Gestión del Fondo especial de garantía de accidentes del trabajo en la industria, etc...

Organización: Reforma de 15 de Junio de 1938.

Su gobierno corresponderá directamente al Consejo y Comisión Permanente de la misma. Al frente de la Caja habrá un Director nombrado por el Ministerio del Trabajo.

Operaciones: Para la práctica de sus operaciones, se emplean las bases técnicas que señala el art. 43 de los estatutos.

Patrimonio: Tendrá un capital funcional de 500 mil ptas. constituido por el Estado; las primas que con arreglo a las tarifas le sean satisfechas; las subvenciones o donaciones que perciba de toda clase de entidades, corporaciones o particulares.

\section{Fondo de Garantía:}

Tiene como fin satisfacer las rentas o indemnizaciones procedentes por incapacidad permanente o por muerte en el accidente del trabajo, cuando resulten insolventes el patrono, la Mutualidad o la Sociedad Mercantil. Una vez efectuado el pago, corresponderá a la Caja Nacional ejercer los derechos y acciones reconocidos al obrero víctima del accidente, contra el que no pudo cumplir con la obligación de indemnizar. Gozará 
del beneficio de pobreza y tendrá acción directa sobre los bienes del patrono, Mutualidad o Sociedad Mercantil.

\section{Seguro Voluntario:}

El seguro será voluntario en lo referente al establecimiento de garantías cuando se trate de Asistencia sanitaria e incapacidad temporal.

Por orden del 16 de Febrero de 1940, quedó también autorizada la Caja Nacional para practicar el seguro de riesgo de incapacidad temporal. Así la Caja podrá cumplir con su fin primordial, que tiene el carácter de prestación social de alta categoría moral y humanitaria.

\section{F) Inspección y Jurisdicción:}

La Inspección Nacional del Trabajo se éncarga de garantizar con Bu vigilancia el cumplimiento de los preceptos legales y reglamentarios sobre accidentes del trabajo y de cuanto afecta a la seguridad e higiene del obrero en las industrias y trabajos.

En cuanto a la jurisdicción, hasta 1938 la jurisdicción en materia de accidentes del trabajo venía determinada por el art. 210 del Reglamento de 31 de Enero de 1933. De acuerdo con este Reglamento, el obrero tenía derecho a reclamar ante las autoridades administrativas y a demandar al patrono por la vía judicial. Por el Decreto de 1938 se suprimen los Tribunales Industriales y se declaran competentes en los iudicial las Magistraturas del Trabajo, y donde no las hubiera el Juez de $1^{a}$ Instancia.

En lo administrativo los reclamos seguirán haciéndose de la misma forma que antes de 1938.

El procedimiento contencioso a seguirse ante las nuevas Magistraturas del Trabajo es fijado en el Libro IV del Código de Trabajo.

\section{ACCILENTES DEL TRABAJO: EN LA AGRICULTURA}

La legislación de accidentes del trabajo no se aplicó al mismo tiempo a la industria y a la agricultura. La opinión general fué durante muchos años adversa al seguro agrícola y fué porque la legislación de accidentes del trabajo debió su origen al maquinismo industrial y pocos fueron los que no se imaginaron: las labores del campo como faeías sin riesgo de ninguna clase desarrolladas en un medio ideal para el desarrollo físico y moral del hombre. Sin embargo poco a poco se fueron dando cuenta los gobiernos de la realidad y en 1921 se firmó un Convenio Internacional en el que se pedía ee extendiera a todos los asalariados de la agricultura los beneficios de las leyes y reglamentos que tienen por objeto irdemnizar a las víctimas de accidentes. En España se extendió la legislación de accidentes del trabajo a ios agricultores solamente en 1931 por Decreto fecha 12 de Julio y la ley de 9 de Septiembre, después de varios infructuosos intentos en 1919 y 1921. 


\section{Campo de aplicación.}

Como la ley de 1931 no hace sino aplicar a la agricultura la legislación ya existente para la industria, es poco lo nuevo que deberemos estudiar en este capítulo.

¿Quienes son trabajadores agrícolas? Los que ejecutan habitualmente en el campo un trabajo fuera de su domicilio por cuenta ajena.

¿Quienes se consideran patronos? "Las personas naturales o jurídicas por cuya cuenta se realizan los trabajos agrícolas o forestales, en concepto de propietarios, aparceros, arrendatarios, subarrendatarios, usufructuarios, enfiteutas, etc...; y las personas que exploten o tengan a su cargo la ejecución de dichos trabajos, en virtud de contrato, con cualquiera de los antes citados."

Sin embargo la responsabilidad patronal sólo se extiende a los trabajos que específicamente señala el art. $8^{\circ}$ del Reglamento.

\section{Riesgo Cubierto.}

Lo que dijimos para la industria es aplicable aquí también. No hay responsabilidad del obrero cuando el accidente se debe a fuerza mayor, rayo insolación u otros fenómenos análogos de la Naturaleza; ni cuando provenga de imprudencia profesional.

\section{Prestaciones.}

Son también de dos clases, sanitaria: asistencia médica y farmacéutica; económica: indemnización en metálico que se determine.

Asistencia sanitaria: es semejante en todo a la de la industria, excepto en un punto: en la agricultura el patrono deberá forzosamente pertenecer a una Mutualidad, la que le reemplazará enteramente. Sólo aquellos patronos que empleen diariamente más de 100 obreros podrán exceptuarse de esta obligación si ellos mismos ofrecen las suficientes garantías de orden asistencial.

Indemnizaciones: también son parecidas a las industriales, pero tienen sin embargo una diferencia fundamental: al obrero con incapacidad permanente o muerte se le abonará un capital y nó una renta. Este capital será equivalente a dos años de salario si hay incapacidad permanente $y$ absoluta; de 18 meses si hay incapacidad permanente y total para la profesión habitual y de un año si hay incapacidad permanente y parcial para la clase de trabajo que es habitual al obrero.

Si hay muerte, la indemnización se hará a los derechohabientes.

Como excepción a la regla que hemos anotado más arriba, la ley permite en casos especiales que el patrono conceda a los derechohabientes una pensión vitálicia si así lo prefieren.

En caso de incapacidad temporal, el obrero recibirá, durante su convalescencia, una cantidad igual a las tres cuartas partes de su salario. 


\section{Ciarantias:}

Ya hemos explicado la necesidad de pertenecer a las Mutualidades para la asistencia sanitaria. En lo referente a la prestación económica, deberá existir un seguro, ya sea con una Mutualidad, ya sea con una Compañía Mercantil.

La Caja Nacional de Seguros de Accidentes, tendrá también un fondo especial de garantía agrícola, para indemnizar a los accidentados o a sus derechohabientes en caso de insolvencia del patrono o de la entidad responsable.

Cabe también en la agricultura el reaseguro.

\section{CAPITULO III}

\section{SUBSIDIO DE VEJEZ}

\section{A).- Objeto y Fuentes:}

Dice Lóprz Núñez: "La resolución del prob!ema de la vejez, interesa a la sociedad y al Estado... Interesa a todos rosolver el arduo prob'era de la subsistencia de los ancianoz pobreg; en su aspecto postivo por el decho que tienen a la vida, y en su aspecto negativo, por ahorar a la colectividad los daños que derivas del abandono."

CComo reso?verio? "Dende al punto de rista económico- añade el autu citado - bólo la institución dé seguro puededar, hoy por hoy la soitición del pavoroso problema de la invalidez de los ancianos."

No podemos hablar propiamente de riesgo en la vejez, y es por esto que casi todas las legislaciones tratan del seguro de vejez en la "invalidez", que comprende dos capítulos:

a) Invalidez por edad (vejez).

b) Invalidez prematura (invalidez propiamente dicha).

Pero nuestro pais, desgraciadamente, no ha estudiado aún la invalidez promalura y solamente legisla lo relativo a la vejez.

El seguro de vejez fué implantado primero en Alemanix en 1889 Hoy puede decirse que todos los países han legislado sobre este punto.

Veamos ahora en forma esquemática el proceso evolutivo que ha iseguido en España la protección a la vejez.

1908: Aparición del Instituto Nacional de Previsión.

Este Instituto fomentó primeramente el Seguro Social volumtario subsidiado por el Estado: pensiones libremente contraídas por el interesado y que el Poder público se obligaba a beneficiar como premio a ese impulso voluntario de previsión.

Enseguida apareció el Seguro Social obligatorio con el "Retiro Obrero" (Decreto de 11 de Marzo de 1919).

Características esenciales del Retiro Obrero:

a) Comprende a los asalariados de 16 a 65 años de edad. tro mil pesetas.

b) Estos asalariados no deben tener un haber anual superior a cua- 
El riesgo que se protegía era el de invalidez por edad. Al cumplir los 65 años, el trabajador podía reclamar los beneficios del seguro.

Sin embargo, la protección dispensada no era la misma para todos los trabajadores. Se establecieron dos grupos formados por:

a) Trabajadores que se hubieran afiliado por primera vez al régimen de seguro antes de cumplir 45 años. Estos recibían a los 65 años, 365 ptas anualmente.

b) Trabajadores que no se hubieran afiliado antes de los 45 años.

A estos se les abría una libreta de capitalización para la anciani. dad, donde se iban acumulando las cotizaciones y bonificaciones del retiro, devolviendo el capital al interesado al cumplir los 65 años o antes si se invalidaba. Si fallecía sin haber cumplido los 65 años, el capital sería entregado a sus herederos. Estado.

Los recursos para el Retiro Obrero procedían del patrono y del

El patrono entregaba mensualmente tres pesetas por obrero. El Estado doce pesetas anuales por asegurado.

Ultimamente hemos adoptado el Subsidio de Vejez, que constituye el régimen actual (ley de $1^{\circ}$ de Septiembre de 1939, consecuencia de lo anunciado en 1938 por el Fuero del Trabajo).

Tiene el fin primodial de dotar a los trabajadores ancianos de un retiro suficiente. Todas las instituciones de seguros sociales tienen un lazo de unión con la Asistencia. En el caso de la ley de $1^{\circ}$ de Septiembre de 1939 no cabe duda que existe, y muy fuerte. Su preocupación fundamen. tal no es la de proteger a los trabajadores ancianos y por ser trabajadores, sino la de proteger a los ancianos sin recursos, por su condición de seres humanos, ofreciéndoles un auxilio igual para todos, que les garantice un minimun de vida, auxilio en el cual el interesado no participa.

Naturalmente ha sido necesario algun tiempo para adaptar el antiguo sistema del Retiro al nuevo del Subsidio, pero podemos decir que ya desde 1940 está funcionando el nuevo sin tropiezos, y a partir de 1945, habrán entrado sus disposiciones en pleno vigor.

\section{B) Campo de Aplicación:}

En el régimen de subsidio de vejez deberăn estar asegurados obligatoriamente todos los trabajadores de ambos sexos, que reunan las con. diciones siguientes:

túan:

a) Trabajar por cuenta ajena. De esta condición general se excep-

$1^{\circ}$ Los funcionarios y obreros del Estado, Diputaciones, Cabildos, Mancomunidades y Ayuntamientos que tengan derecho a jubilación.

$2^{\circ}$ Los servidores domésticos, a pesar de que es cada día mayor la tendencia a considerarles no como criados de un amo, sino como trabajadores de un patrono.

En general se comprenden pues en la masa de trabajadores con derecho al subsidio de vejez a todos los que se emplean en actividades industriales o agrícolas, y en cuanto a éstos últimos, la ley de 10 de Febrero de 1943 no hace distingos entre los que trabajan por cuenta ajena y los autónomos. Sin embargo es necesario esperar a que aparezca el Reglamento de la citada ley, para conocer las condiciones que se aplicará al subsidio. 
La corriente en todo el mundo es favorable, hoy en día, a la incluNón en el subsidio de vejez, de la totalidad de los trabajadores, ya sean independientes o nó, ya que de otra manera no podría decirse de una institución de seguros sociales que cumple con su misión de proteger a los económicamente débiles contra los riesgos de la vida y del trabajo, si sólo protege a los que desarrollan una actividad por cuenta ajena. La ley de $1^{\circ}$ de Septiembre de 1939 se ocupa de este punto y disposiciones ministeriales complementarias verán la forma de su realización.

b) Limitaciones en razón a la edad:

La obligación de estar afiliado al subsidio de vejez comienza a ios 16 años y termina a los 65. El límite inferior está señalado en 16 años por ser ésta la edad normal para el comienzo de las actividades profesionales. El límite superior de 65 años es también el del retiro del obrero.

La legislación española establece sin embargo, que a partir de 1945 la edad límite superior para la afiliación será 60 años, debiendo haber un "stage" o "periodo de carencia" de cinco años, para que el trabajador pueda exigir su subsidio. Durante este periodo de carencia el patrono seguirá abonando las cuotas del obrero.

c) Limitación por razón de las ganancias:

Cuando se implantó el sistema del retiro, se fijó un límite de ingresos de cuatro mil pesetas para el obrero, pero con el nuevo sistema del subsidio, éste se ha ampliado hasta nueve mil. Esta modificación nos parece muy acertada, ya que ha habido un alza indiscutible en el coste de vida, alza que de no tener su natural retribución, perjudicaría grandemente a! trabajador económicamente débil. Sin embargo las percepciones extraordinarias (gratificaciones, pluses por carestía de vîda, etc...) no merecerán estar incluidas entre los ingresos normales, que como dijimos no deberán pasar de las nueve mil pesetas.

\section{Afiliación :}

La obligación de afiliar a los obreros que trabajan por cuenta ajena, en el subsidio de vejez, corresponderá al patrono. Las obligaciones patronales son pues fundamentalmente:

1 . Afiliar a los trabajadores a sus órdenes.

$2^{\circ}$ Liquidar al órgano asegurador las cuotas o primas que tal obligación les imponga.

La afiliación deberá realizarla el patrono mediante el empadronamiento y ante la Delegación provincial del Instituto que corresponda.

Los patronos deberán exponer en lugar visible para que puedan examinarlos los obreros, los padrones de afiliación y los boletines de liquidación de cuotas.

El art. $9^{\circ}$ de la ley de 10 de Febrero de 1943 establece que para los trabajadores agrícolas, la afiliación se hará a través de la organización sindical de cada término municipal. 


\section{C) Riesgo Cubierto y Prestaciones.}

Cuando se habla de subsidio de vejez, se refiere uno a la protección dispensada al inválido por edad. Se trata de un régimen de jubilaciones para trabajadores, con una prestación consistente en 90 pesetas mensuales (subsidio o pensión).

Ya conocemos las condiciones de concesión: edad, tiempo de afiliación, carencia de otros ingresos, etc...pero quisiera aclarar un punto interesante con respecto a la segunda condición mencionada. Hemos dicho que a partir de los 65 años, el obrero que lleva por lo menos cinco años de afiliado al subsidio, tiene derecho a exigir su prestación. Pero ćcual será la situación del que llegue a esta edad sin tener todavía los cinco años cumplidos de afiliación? La ley dice que en este caso si el obrero está interasado en el subsidio - como es de suponerse - podrá seguir trabaíando hasta completar lo que antes llamamos el periodo de carencia (cinco años) y durante este periodo el patrono continuará abonando sus cuotas. Cumplida esta condición el obrero entrará a gozar inmediatamente del beneficio del subsidio.

\section{Requisitos:}

El propio interesado deberá solicitar el pago del subsidio de vejez, del órgano asegurador, mediante instancia dirigida al Instituto Nacional de Previsión. El subsidio se abona hasta el día en que el subsidiado fallece. Se pagará integramente el subsidio correspondiente al mes de su fallecimiento a sus derechohabientes.

\section{D) Régimen y Recursos.}

Los recursos económicos para el pago del subsidio de vejez proceden de dos fuentes principales: Patronos y Poderes públicos. Además hay otros de relativa importancia, como son las subvenciones (entre ellas una especial en Fresupuesos, concedida por la ley de Reforma tributaria de 1940. en substitución del recargo sobre la herencia, que fué suprimido), donativos - legados recibidos por el Instituto Nacional de Previsión. Pero lo fundamental de la legislación del subsidio, en cuanto a 'los recursos, es que mantiene la tendencia a no incluir a los asegurados en la obligación de cotizar, a concederlo todo gratis, como en realidad corresponde a un régimen asis. tencial.

La cuota del patrono será del $3 \%$ de las retribuciones de sus obreros. La aportación del Estado será la subvención fijada en sus presupuestos, con tal objeto. Esta subvención procedente del Presupuesto Nacional llevará el nombre de Fondo: de Bonificaciones.

En la ley de $1^{\circ}$ de Setiembre de 1939, se aludía a la posibilidad de cobrar las cuotas patronales junto con el pago de la contribución territorial. La posibilidad prevista en la ley del 39 se ha convertido en réalidad con la ley de $1^{\circ}$ de Febrero de 1943, sobre régimen especial de los seguros sociales en la agricultura, que abarca no solamente el subsidio de la vejez en el campo sino al familiar. 
E) Administración, Jurisdicción e Inspección,

Adminisuración.

La crganización, gestión y administracion del régimen de subsidio de vejez está encomendada al Instituto Nacional de Previsión.

Ls pues el Instivto, el órgano encargado de recibir las cotizaciones de los patronos, de administrar estas, $y$ de hacer éfectivas las prestaciones a los trabajadores asegurados.

\section{Jurisdicción:}

Cabe que surjan conflictos: patronos.

a) Entre los órganos de gestión del régimen y ios asegurados o

b) Entre los asegurados y patronos.

En el primer caso, los interesados podrán recurrir ante la Dirección General de Previsión. En el segundo caso la autoridad competente es el Magistrado del Trabajo. Contra la sentencia de cualquiera de estas autoridades cabe recurso de casación ante la Sala Social del Tribunal Supremo. Inspección: el órgano encargado es la Inspección del Trabajo.

\section{CAPITULO IV}

\section{SEGURO DE MATERNIDAD}

\section{a) Objeto y Fuentes:}

La maternidad no es en sí un riesgo sino un acontecimiento natural y deseable, pero si no se desenvuelve dentro de un mínimo de condiciones de tipo higiénico, da origen a una morbilidad y a una mortalidad en las madres y en los hijos, verdaderamente catastróficas. El seguro de maternidad persigue pues proteger a la madre embarazada y al hijo que nacerá, evitando por todos los medios a su alcance que se produzcan enfermedades, y si se producen trata de curarlas y evita que se propaguen.

En aquellos países donde existe aun seguro de enfermedad se ha creado un seguro especial para el riesgo de maternidad. En España se estableció el seguro de enfermedad por ley de 14 de Diciembre de 1942, que deberá encargarse del de materridad que le ha antecedido, pero to- 
davía no han entrado en vigor sus disposiciones y ambos seguirán funcionando mientras tanto independientemente.

La finalidad del seguro de maternidad es doble:

En primer lugar tratará de resolver el problema sanitario planteado por la morbilidad y mortandad de las madres trabajadoras económicamente débiles y de sus hijos.

En segundo lugar, impondrá a la madre, antes y después del parto, un descanso obligatorio, y mientras dure "éste le proporcionará su salario normal garantizándole la conservación de su empleo durante su ausencia.

\section{Disposiciones legales vigentes:}

Los trabajos que efectuó el Instituto Nacional de Previsión dieron cuerpo al seguro de maternidad vigente que fué implantado entre los años 29 y 31 y perfeccionado por leyes posteriores como las del 40, 41 y 42. Podemos decir también que, desde el año 1900, España se ha preocupado activamente de este problema y ha dispensado en diversas formas su protección a las mujeres sujetas al riesgo de maternidad.

\section{b) Campo de aplicación:}

Aseguradas. - $1^{\circ}$ ) Las mujeres afiliadas al seguro de vejez, y que por lo tanto, trabajan por cuenta ajena y no tienen ingresos superiores a nueve mil pesetas al año. Cuando empiece a aplicarse el seguro de enfermedad, que ha de abarcar al de maternidad, quedarán también aseguradas las trabajadoras en el servicio doméstico.

2) Las mujeres cuyos maridos estén afiliados al Subsidio Familiar y que podrán por lo tanto, tener ingresos superiores a nueve mil pesetas.

3) Las mujeres que están afiliadas directamente al Subsidio Familiar.

En cuanto a la edad establecida para la afiliación hay un límite mínimo de 16 años y máximo de 60 , período durante el cual el seguro obliga a cotizar. Fuera de este período el seguro protegerá los casos poco frecuentes de maternidad, gratuitamente.

El estado civil no se tomará en cuenta y la obligación de cotizar corresponderá a casadas, solteras y viudas.

Las aseguradas acreditarán su afiliación a! seguro mediante una tarjeta de identidad que éste les entregará gratuitamente.

Afiliación.-1) En el caso de las trabajadoras por cuenta ajena y con ingresos inferiores a nueve mil pesetas, será el patrono el obligado a efectuar la afiliaçión.

2) Cuando las trabajadoras tengan ingresos superiores a nueve mil pesetas $y$ ellas o sus maridos estén afiliados al subsidio familiar, será la Caja Nacional de Subsidios Familiares la institución encargada de su afiliación.

El patrono será responsable de la no afiliación de trabajadoras a sus órdenes y esta falta no perjudicará en ningún caso a la madre. 


\section{c) Prestaciones:}

Serán de dos clases: en metálico y en especie.

La prestación an metálico indemnizará a la trabajadora: 1) por la interupción o descarco obligado a que la ley le someta por espacio de seiz semanas posteriores al parto y por las semanas inmediatamente anteriores que solinite la trebajadora. 2) Por los gastos extraordinarios de nutrición que deberá hace: la madre que lacte a su hijo. Esta indemnización se llama subeidio de lactancia.

En el primer caso la indemnización será de noventa a ciento ochente peretas.

W. croundo de cincuenta pesetas.

La pescacion en especie comprende asietencia facultativa gratuita do matrone. médico y farmacia. La matrona estará encargada de los parton nomalen : aplicación de inyecriones y demás servicios que el médico le encomicncí. Fl médico reconocerá a la enferma durante el periodo de gestación $y$ an encargará de los partos anormales y veíará también por la salud ie madre y del hijo durante las seis remanas posteriores al parto. Con objoto de facilitar la asistencia faculativa a las asegurados el Instituto Nacional de Previción (que es el organismo asegurador) ha concertado esos servicios con los Colegios Médicos y Farmacénticos y con las Organizaciones de Matronas. El securo de maternidad aspira a la constitución de una red de instituciones protectoras de la matemidad $y$ de la infancia, tales como Escueles de Puericultura, Dispensarios, Maternologías. etc... y a facilitar su utilización gratuita a las asecuradas. Con esto se pretende evitar la mortalidad en lo posible tanto de la madre como del hijo.

\section{d) Recursos económicos y régimen financiero:}

Recursos.-En el primer grupo de afiladas que hemos señalado antes, o sea aquel en que las mujeres trabajan por cuenta ajena y no tienen ingresos superiores a nueve mi peselas. Oos recursos procederán del Poder público, los patronos y las aseguradas. Los patronos esterán encargados de pagar la cuota asignada a la trebajadom y cieberán recaudar la suma correspondiente mediante la reduccion consigaente dal respectivo salario.

Régimen financiero. Escuetamente potemos decir que el seguro está organizado dentro del institute como comeponcle d un oeguro le ricsor a cotio plazo, en romen de reparto. Pero el lecisiador ha estable. cido además ierto fondos especiales (Je Reserva, Matenal e Infanil, Indemnizariones especiales y Reculador) con \& fin do protar morores garantías economicas a la institación

\section{e) Administración e Inspección:}

Eera el propio Instituto Nacionai de Previon é encargedo de la ad-

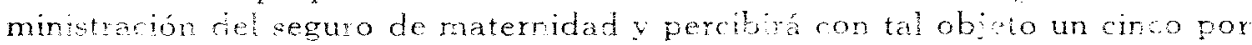
cienco dis la cota de patronos y aseguradas. Para la mopecón existiná un cuepo de médics y visitadorea que deberá comprobar continuamente 
la eficacia del servicio pactado. Los gastos que ocasione esta inspección serán pagados con otro cinco por ciento de las cuotas patronales y de las aseguradas.

\section{CAPITULO $\mathrm{V}$}

\section{SUBSIDIOS FAMILIARES}

El régimen del subsidio familiar tiene por objeto ayudar al obrero a soportar la carga que supone el sostenimiento de una familia. Para este seguro el riesgo no consiste en tener familia; sería monstruosor aceptar esto, el riesgo está en no disponer de los medios económicos suficientes para mantenerla. La situación económica del obrero durante el siglo XIX $y$ principios del XX ha sido mala y no le ha permitido formarse una familia numerosa, razón por la cual muchos países se han visto confrontados con el trágico problema de la despoblación. Ha sido pues en bien del individuo en particular y de la sociedad en general que se ha implantado este régimen del subsidio familiar.

\section{Iniciativas para proteger la familia: el "salario familiar".}

La única iniciativa que se ha tomado ha sido la del salario familiar, que, según opinión del gran tratadista español Aznar, deriva de la Encíclica Rerum Novarum de León XIII. Dice Aznar: el obrero no dispone de más medios económicos que su salario, luego o se le niega el derecho a tener hijos y el deber de mantenerlos o la remuneración que reciba tiene que ser suficiente para ello, debe ser familiar.

Ha habido tres opiniones en cuanto a la manera de llevar a la práctica la idea del salario familiar.

La primera sostiene que cada cual debe tener un salario mínimo proporcional al volumen de su familia.

familia normal.

La segunda pretende que el salario sea suficiente para sostener una

La tercera, que se suplemente el salario o sueldo que gane el trabajador con un subsidio proporcional a sus cargas de familia.

Las dos primeras soluciones no han tenido éxito y ha sido la tercera que ha triunfado. Evidentemente que esta solución importa cierto riesgo a las empresas que tengan personal con familias numerosas, ya que no podrían hacer distinciones al emplearlo, y es por esto que surgieron las Cajas de Compensación, que según definición de Jordana, son "asociaciones constituídas por entidades patronales, con el fin de repartirse entre ellas, según la importancia de su empresa, la carga de los subsidios familiares pagados a su personal". Pero las Cajas de Compensación demostraron ser insuficientes y se ideó el sistema del seguro familiar que transigió con el régimen anterior pero imponiéndole dos condinones: 1) que las Cajas fueran generalizadas por medio de contratos colectivos de trabajo o por la obligación impuesta por el Estado, 2) que estuvieran sometidas al control efectivo del mismo. 
Etapas en la introducción del seguro:

Las leyes más notabies que han marcado etapas en la historia de ecte seguro hen sido la Belga de 1930, la Italiana de 1937 y la Española de 1938 , que es la que más se adapta a las condiciones de los securos so. ciales y la más perfecta hasta la fecha.

Lexislación espã̃ola:

El régimen del subsidio familiar vigente en España nació por ley de 18 de Julio de 1938 y su Reglamento lué aprobado por Decieto de 20 de Octubre de! mismo año. Posteriormente ha sufrido algunas rnodificaciones, como la de 22 de Febrero de 1941, que mejoró los subsidios y cré los préstamos de nupciaiidad y las primas a la natalidad, y la de 12 de Marzo de 1942, que alteró el sistema de pagos.

Anteriormente a esta ley básica solamente hubo un Decreto Ley de 21 de Junio de 1926 (iniciativa del Sr. Aunós) que concedía ciertas ventajas de índole económica a las familias de más de ocho hijos. La ley actual no se ha dictado para que las familias tengan más hijos, sino con el propósito de que puedan criar los que tuvieren y no se les presente esta obligación como un pavoroso problema de miseria.

\section{B) Campo de aplicación:}

Pueden acogerse al régimen del subsidio familiar todos los trabajadores que están al servicio de otro, sin limitación alguna por la cuantía de sus ganancias. Solamente están eximidos los servidores domésticos y los que tienen algún lazo de parentesco con el patrono. afiliados.

La legislación vigente distingue entre asegurados, beneficiarios y

Asegurados: reciben este nombre todos los españoles que trabajan por cuenta ajena (debiendo estar el patrono afiliado), cualquiera que sea su edad, estado civil, sexo, forma y cuantía de su remuneración. (Art. 9 R.).

En las actividades agrícolas, forestales y pecuarias deberán asegurarse todos los trabajadores, lo mismo si trabajan por cuenta ajena, que por cuenta propia. La habitualidad en estas actividades, cuando el trabajo es por cuenta ajena, se establece poniendo un límite mínimo de noventa días al año.

Este régimen alcanza también a los súbditos extranjeros si hay reciprocidad de trato con los españoles en sus respectivos países. Desde luego están equiparados a los trabajadores españoles los súbclitos portugueses, andorranos, e iberoamericanos (art. 9 R.).

Subsidiados: reciben esta denominacín todos los asezurados con derecho a percibir subsidio por tener beneficiarios a cargo (disposición preliminar R.). La ley de $1^{\circ}$ de Septiembre de 1939 complementada por la Orden de 7 de Diciembre del mismo año, modificada por la de 11 de Junio de 1941 , dispone todo lo relativo al subsidio de vindas y huérfanos.

Beneficiarios: se llaman así las personas en atención a las cuales se conceden los subsidios a los asegurados, que se transforman por este 
hecho en subsidiados.

Poseen lá condición de beneficiarios los hijos legítimos naturales reconocidos y los hijos del cónyuge; lo serán igualmente los nietos o hermanos del asegurado que no tengan por otro motivo derecho al subsidio y cuyos padres hayan muerto o estén incapacitados para el trabajo. Todos ellos deberán reunir las condiciones de vivir en España, en el hogar del subsidiado y a su cargo, y no tener más de catorce años. Si el beneficiario que cumple los catorce años acredita que está cursando estudios de enseñanza media o de formación profesional, se seguirá otorgando el subsidio hasta que cumpla dieciocho años de edad.

La afiliación es obligatoria para todos los patronos que empleen obreros, empleados o funcionarios, cualquiera que sea la clase de trabajo a que les dediquen o la cuantía de la remuneración que les paguen.

\section{C) Riesgo cubierto y prestaciones:}

El riesgo en este seguro consiste en tener beneficiarios a cargo. El asegurado que tiene beneficiarios recibe un subsidio y se convierte así en subsidiado.

El auxilio económico en que consiste este subsidio tiene las cuatro características siguientes:

a) es igual para todos los subsidiados y proporcional al número de beneficiados.

b) no cabe percibir más de un solo subsidio por familia.

c) es inalienable.

d) no forma parte del salario, no es supersalario.

Beneficios o prestaciones: la determinación de la prestación puede hacerse por mes o por día y para ello existen escalas especiales. La más reciente es del año 1941. Para que el cálculo sea hecho por mes es necesario que el asegurado haya trabajado por lo menos cinco días al mes en la empresa afiliada. La gran mayoría de los subsidios son calculados por la escala mensual. Hay una reglamentación especial para los trabajadores a domicilio:

\section{ESCALA DE SUBSIDIOS:}

Número de hijos

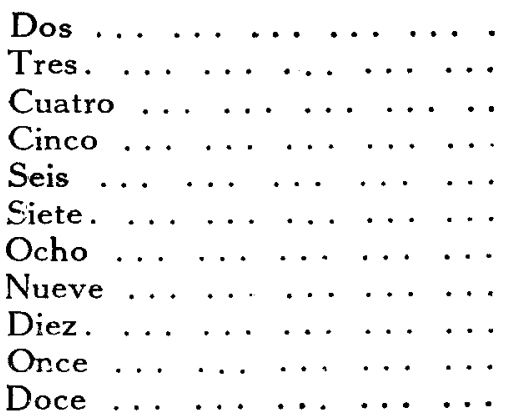

Mensual: pesetas

treinta

cuarenta y cinco

sesenta

ochenta

cien

ciento veinte

ciento cincuenta

ciento ochenta

doscientos diez

doscientos cincuenta

doscientos noventa
Diario pesetas

1,20

1,80

2,40

3,20

4,00

4,80

6,00

7,20

8,40

10,00

11,60 
Por cada hijo o asimilado a estos que excede de los doce, se adicionará en cincuenta pesetas el subsidio mensual, y, en proporción corxespondiente el diario.

Esta escala tiene sus excepciones como en el caso de la viuda del trabajador asegurado que tiene derecho al subsidio sin necesidad de tener hijos, o e! caso del trabajador asegurado viudo que teniendo un solo hijo tiene ya derecho a percibir por él treinta peseras mensuales, que es la cantidar oue según la escala le correspondería si tuviera dos hijos.

Los articulos 17,19 y 20 del Reglamento, hablan del cómputo en los períodos, de las mejoras y de la prescripción de los subsidios.

El subsidio se paga por regla general al propio asegurado. Sin embarzo podrá haceree efectivo a la madre de los beneficiarios en algunos casos o a los propios benticiarios si murió el asegurado, o a las personas que tuvieran a ea cargo a los huérfanos.

\section{D) Pecuros y regrmen financiero:}

Los vecursos eronómicos que hacen posible este végmen del subsidio farriliar proceden de tyes funtes: ei Estado, é petrono $y$ el asecrurado.

E Estado entregó a la Caja Vacional de subsidios familiares como capital fundaciorel cinco millones de pesetas $y$ anamente contribuye con we abvención de ocho millones.

Los patronos (afiliados) contribuyen con una cuota igua! al seis for ciento de las retibuciones que hagan a sus empleados.

los asecurados pagaxán una sexta parte de la cuota del patrono o sea $\epsilon$ ! uro por ciento de su salario. El payo íntegro de la cucta correspon. derá al patrono. cue deducirá el sexto correspontiente a cada trabajador del salario de éste al momento de hacérselo efectivo.

En las activitades agropecuarias, los patronos deberán soportar la totalidad de la cunta oue eerá calculade de acuerdo con la contribución

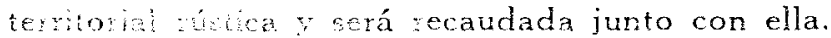

F cenuo do stosidio familiar está organizado financieramente en sistema de yereto con fordo de reserva o garantía.

1) Adrexistración y gestión:

I. Ca Narona de Subsidos Familiares monstuye dentro del Ins-

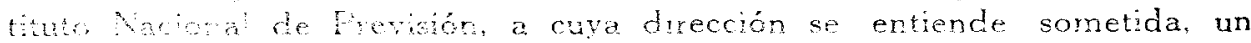

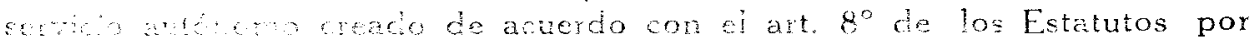
que esto se sobiema.

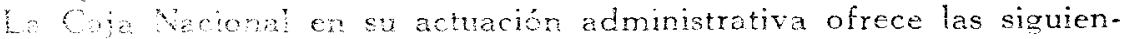

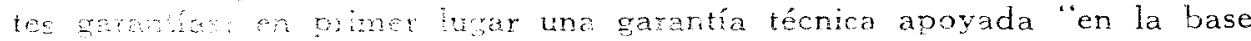
chonfifa que inome la dotominación de las cuotas revisables cada año $y$ en tora su nrganiwacion y regmon, rigurosamente técho y an a enome ma sa de acomodo que fa de terer". En segurdo lugar ma garantía finan cen. "ave derina do los recursos bien estidiedos con que re la dota y que se cucuentrom cobustecidos por los fordos de reserva que por imperativo de 'a Les y dea Reglamento ha de constuir y conservar la Caja". Hay, pc itimo, una tercera grantia la que ofrece la untervención $y$ constante vighancis dé Ededo con su triplo carácter de administrativa. financiera y 
actuarial; la administrativa que se ejerce por medio del Presidente del Consejo del Instituto que es el Ministro del Trabajo; la financiera y la actuarial por la Comisión revisora que anualmente designa el Ministro y que deberá comprobar la exactitud del balance, la conformidad entre la recaudación y las cuotas individuales, etc.

\section{F) Inspección y jurisdicción :}

La inspección del régimen de subsidios familiares se ejerce por la Inspección del Trabajo. Los inspectores y sus delegados tendrán la facultad de exigir a los afiliados la exhibición de su contabilidad, la presentación de las nóminas de su personal y de sus libros de matrícula, etc.

El Reglamento enumera los actos que constituyen infracciones y las sanciones que como tales merecerán.

\section{G) Préstamos de nupcialidad y premios a la natalidad:}

Con los excedentes de que dispone la Caja Nacional de Subsidios Familiares ha permitido el Estado la creación de varios servicios sociales que completan la obra del régimen de subsidio familiar y contribuyen poderosamente el afianzamiento económico de la unidad social y al robustecimiento de la política demográfica nacional. Son estos servicios: los préstamos de nupcialidad y los premios a la natalidad.

a).-Préstamos de nupcialidad: Fueron creados por Decreto de 22 de Febrero de 1941. Funcionan de la siguiente manera: anualmente anuncia la Caja Nacional de Subsidios el número de préstamos a concederse en el territorio nacional y especifica cómo han de ser distribuídos entre las provincias y en qué meses. Todo el que desee obtener un préstamo deberá solicitarlo a la Delegación Nacional de Previsión, la que mensualmente anunciará públicamente el resultado del concurso.

Si el solicitante es varón deberá reunir las siguientes condiciones: 1) estar asegurado en el régimen del subsidio familiar, 2) ser soltero, 3) tener en el momento del enlace menos de treinta años, 4) contraer matrimonio con mujer soltera, 5) que el importe total de sus ingresos no sea superior a diez mil pesetas.

Si es mujer: 1) haber trabajado en los dos años anteriores al matrimonio por lo menos nueve meses; 2) ser soltera, 3) tener menos de 25 años, 4) no tener ingresos superiores a diez mil pesetas, 5) comprometerse a renunciar a su ocupación laboral y a no tener otra análoga mientras su esposo pueda trabajar normalmente.

En la concesión de préstamos tendrán preferencia aquellos que tengan a su cargo padres sexagenarios o hermanos menores de catorce años.

Solamente se concederá un préstamo por matrimonio. El préstamo será entregado por la Delegación provincial del Instituto y en el acto mismo de contraerse el matrimonio.

Los concesionarios de los préstamos de nupcialidad gozarán de los siguientes beneficios:

a) bonificación del $25 \%$ del saldo pendiente de pago por el nacimiento de cada hijo legítimo. 
b) cancelación total del préstamo al nacer el cuarto hijo.

c) no soportar la obligación de pagar interés de ninguna clase.

d) podrán obtener a petición propia la suspensión de las entregas mensuales por piazos de seis meses en los periodos posteriores a cada parto.

Asimieno los prestatarios tendrán ciertas obligaciones, como la de destinar el importe de los préstamos a la constitución del hogar de familia, la de conservar los comprobantes de la inversión del préstamo para su inspección por la Caja Nacional, la de reintegrar el importe del mismo (cuando no pueden beneficiarse con lo dicho anteriormente). La reintegración se hará mediante entregas mensuales equivalentes al 1 ? del importe total del préstamo.

\section{b)..-Premios a la natalidad:}

Fueron crearlos por Decreto de 22 de Fehrerc to 1941.

Premios establecidos: a) uno raciond de cince mil pesetas para el matrimonio español que mayor número de hijos hava tenido; b) cincuenta premios de mil pesetas que se otorgarán uno en cada provincia el matri monio españo! con domicilio en ela gue hava tenido nayor número de hijoe; c) uro de ino mil pesetas para el matrimonio que conserve e! mayor númer de jos wos el día $!^{\circ}$ de Enero de cada año y d) cincuenta premios de m: nusten a distribuirse por provircias y a otoromse al matrimonio que en ala wa de ellas conserve el lo de Fnewo d ada año el mayor

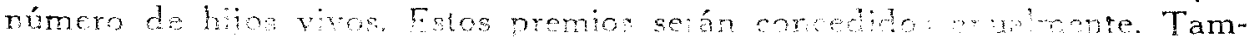

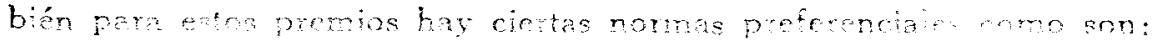

a) el mayor número de hijos que vivan en e! l.... n.... igal.

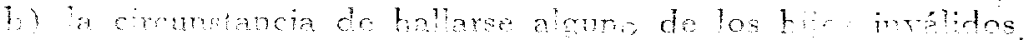

c) el hecho de que alguno de los hijos haya myerio for la patria.

d) irrnal a sue!do inferior del cabeza de familia.

La concesion de los premios se llevará a efecto por la Dirección General de Previsión.

\section{CAPITULO VI}

\section{SEGURO DE SILICOSIS}

Reparación de las enfermedades profesionales.- En muchos países se estudian independientemente los riesgos de accidentes de trabajo $\mathbf{y}$ de enfermedad profesional y se han formado seguros distintos para cada riesgo. Algunos tratadistas buscando la diferencia entre e! accidente y la enfermedad, han llegado a la conclusión de gue no existe, pues dicen que solamente adoptan matices distintos debido al tiempo que tardan en manifestarse. En el accidente el daño se exterioriza con gran rapidez, mientras que en la enfermedad profesional la lesión o trastorno corpcral se adquiere de une manera lenta y gradual.

Es comprensible, sin embargo, que se les haya estudiado separada. mente, pues hasta hace relativamente poco tiempo se encontraba gran dificultad en distinguir entre la enfermedad común y la profesional. Además 
resultaba aún más complicado establecer el origen de esta y su iniciación con el objeto de fijar la responsabilidad patronal.

En España se ha tardado mucho en prestar atención al problema de la enfermedad profesional. Desde 1900 se empezó a regular la reparación de accidentes del trabajo, pero solamente en 1936 se hizo lo propio con la enfermedad profesional.

\section{A) ¿Qué es la Silicosis?}

A todos los trastornos producidos en el pulmón por inhalación de polvos se le denomina neumoconiosis. Cuando esos polvos proceden de la sílice, se llama silicosis a la neumoconiosis que provocan. Especial peligro corren en contraer esta enfermedad los picapedreros, canteros de granito, y arenisca, mineros del carbón y del plomo, molineros (antiguos molinos), afiladores, fibrocementos (asbentosis), ceramistas, etc.

$A_{\mathrm{l}}$ investigar la llamada "tisis de los mineros" a principios de siglo, fué que se descubrió el peligro de los polvos de sílice inhalados a los pulmones.

Africa del Sur fué el primer país (1911) en reglamentar la reparación contra la silicosis como enfermedad profesional. En 1925 se aprobó un convenio internacional sobre la enfermedad profesional, convenio que España ratificó en 1932. La reglamentación de este seguro se hizo indispensable en España debido a las reclamaciones numerosas procedenteo de individuos perjudicados en las zonas mineras del país. En 1942 se estam bleció el seguro de la enfermedad profesional denominada silicosis. El preámbulo del Decreto del 42 decía que el legislador consideraba a la enfermedad profesional comprendida dentro del accidente del trabajo, pero que reconocía que la citada enfermedad adquiría en determinadas industrias caracteres de tal magnitud que aconsejaba encuadrarla en marco pror pio.

Pcr lo tanto si en España se desvincula la enfermedad profesional del accidente de trabajo por razones funcionales, es cierto también que no llegan a romperse sus lazos, y así el nuevo seguro organizado sobre la base de una gran Mutualidad, está sujeto por medio de ésta a la adminis. tración de la Caja Nacional de Seguro de Accidentes del Trabajo. En aquellos casos en que se comprueba la existencia de una enfermedad que no es la silicosis, surgida como consecuencia del trabajo prestado contínuamente en determinada empresa o industria, la indemnización será establecida de acuerdo con las disposiciones del seguro de accidentes del trabajo.

\section{B) Campo de aplicación:}

Estarán comprendidos en el nuevo seguro los trabajadores al servicio de empresas obligadas a proteger a su personal contra el riesgo de silicosis. La ley establece cuáles son las industrias que están sometidas a esta obligación: industrias de carámica en las que existe el peligro de silico. sis, industrias de plomo y de oro y cualquiera otra industria que a propuesta de la Dirección General de Previsión y previo informe de la de Trabajo, se determine por orden ministerial.

El artículo $7^{\circ}$ del Reglamento fija la obligación patronal de afiliar 
a su personal en el nuevo seguro, de abonar con puntualidad las cuotas, de cuidar que anualmente se practique el reconocimiento médico de sus obreros, etc.

En adelante cualquiera nueva industria afecta al riesgo de silicosis deberá estar autorizada por la Sección de Seguro de Silicosis de la Caja Nacional que deberá estar informada de las características de la empresa, del personal que pretenda ocupar y de la producción anual que desee alcanzar.

\section{C) Prestaciones}

Las prestaciones en el seguro de silicosis tienen por objeto indemnizar al obrero perjudicado que sufre incapacidad permanente o muerte. La ley establece tres grados de incapacidad para este seguro e indica para cada grado qué porcentaje del salario deberá ser entregado al asegurado como indemnización. El reconocimiento médico tiene una importancia enorme ya que de él dependerá la declaración de incapacidad, ya sea temporal o permanente, y el establecimiento de la responsabilidad patronal.

\section{D) Recursos económicos y régimen financiero:}

Los reçursos económicos para el seguro provendrán del patrono. En cuanto al régimen financiero empleado, funciona el de reparto de cobertura de capitales.

\section{E) Administración :}

De ella se encargará la Sección de Seguros de Silicosis constituída en la Caja Nacional de Seguro de Accidentes deí Trabajo del Instituto Nacional de Previsión.

\section{F) Inspección y jurisdicción:}

De la vigilancia en el cumplimiento de los preceptos del nuevo seguro está encargada la Inspección Nacional del Trabajo. Cuando el inspector del trabajo compruebe deficiencias en las empresas con respecto a la observancia de las prescripciones del seguro, deberá hacer la denuncia pertinente al Ministerio. Según el artículo 30 del Reglamento podrá también aplicar sanciones.

Las reclamaciones de carácter contencioso serán sustanciadas por la Magistratura del Trabajo y las administrativas por la Dirección General de Previsión. 


\section{CAPITULO VII}

\section{SEGURO DE ENFERMEDAD}

\section{A) Objeto y fuentes:}

La enfermedad como alteración patológica del cuerpo humano puede provenir desde el punto de vista de nuestra legislación social de la actividad laboral, en cuyo caso podrá dar lugar a indemnización por enfermedad profesional, o bien puede obedecer a causas naturales, casi normales, a las que estamos sujetos todos, y la protección que merezca el individuo en este caso procederá del seguro de enfermedad. tres etapas:

El seguro de enfermedad en su proceso de formación ha seguido

a) En la primera vió la necesidad de ayudar económicamente al trabajador enfermo que se encontraba incapacitado para el trabajo. El seguro se limitó a compensarle la pérdida del salario mediante la entrega de una prestación en dinero.

b) En la segunda comprendió la urgencia en dispensar asietencia médica a estos enfermos que, librados a sus propios medios, poco o nada podían conseguir y organizó entonces la asistencia facultativa.

c) En la tercera completó el círculo de protección y no se limitó solamente a curar sino también a prevenir las enfermedades mediante el desarrollo de una intensa acción profiláctica.

Es innecesario hacer resaltar la importancia del seguro de enfermedad; todos vemos que por él protegemos a los trabajadores y a la sociedad en general.

El seguro de enfermedad que surgió en 1883 en Alemania, tardó muchos años en extenderse a los demás países; así en 1914 apenas había media docena que lo aplicaban. Hoy en día la inmensa mayoría de los países tienen este seguro que por fin ha logrado superar las dificultades que se le oponían. Entre estas dificultades creemos que la más importante ha sido la del problema médico. El cambio de fisonomía que al ejercicio de la medicina iba a dar el nuevo seguro, haciéndole perder su carácter marcadamente individual para convertirlo en un arte francamente social, hizo que los médicos asumieran una actitud de desconfianza y temor. Pero han sido tantos y tan grandes los beneficios rendidos por el nuevo seguro que ya hoy en día nadie discute sobre la conveniencia de su aplicación.

\section{Antecedentes en España.}

El interés por el seguro de enfermedad comenzó en España a raíz de la creación del Instituto Nacional de Previsión y cobró impulso en las conferencias de Madrid (1917) y Barcelona (1922) sobre seguros sociales. En 1931 figura la creación del seguro de enfermedad entre las medidas sociales que serían objeto de una regulación. En 1932 se ratificaron dos convenios internacionales sobre este seguro firmados en Ginebra en 1927 . 
En 1936 se aprobó un anteproyecto de unificación de seguros sociales dentro del cual iba englobado el seguro de enfermedad. Finalmente en Diciembre de 1942 quedó implantado el nuevo seguro, cuya aplicación a la práctica ha tardado algunos meses.

\section{B) Campo de aplicación:}

Al seguro obligatorio de enfermedad en España estarán afiliados todos los productores españoles económicamente débiles que con su trabajo intervergan en nuestro país en un círculo cualquiera de la producción, ya sea por cuenta ajena (asalariados) o por cuenta propia (independientes). En este seguro no hay la excepción del servicio doméstico. El Reglamenio no ha fijado aún el límite de ingresos que deberá tener el productor para ser considerado económicamente débil. La ley en su definición limita el seguro a los productores españoles, pero por el art. $6^{\circ} \mathrm{R}$. equipará a éstors los cuidadanos hispano-americanos, portugueses y andorranos. Creemos censurable este criterio de distinguir entre nacionales y extrangeros, ya que é objeto primordial del nuevo seguro es proteger a la sociedad en general contra las enfermedades y además porque el foco de infección que se trata de borrar puede venir lo mismo de unos que de otros.

El seguro español tiene un carácter netamente familiar, pues no se limita a proteger solamente al asegurado sino también a su familia. El art. $8^{\circ}$ L. dice quiénes serán considerados familiares. A estos que así indirectamente reciben protección del seguro se les llama beneficiarios.

La afiliación en el seguro se hará de distinta forma según que el trabajador actúe por cuenta ajena o nó. En el primer caso el obiligado a efectuar la afiliación será el patrono. En el segundo el trabajador deberá incorporarse al seguro a través del organismo sindical que le corresponda.

También se ha previsto en la ley de 1942 la posibilidad de establece: un seguro voluntario para aquellos trabajadores que no sean económicamente débiles, pero que deseen estar protegidos por el ceguro.

\section{C) Prestaciones:} (sanitarias).

Las prestaciones serán en matálico (económicas) y, en especial

Prestaciones leconómicas: se conceden cuando el enfermo reune las condiciones siguientes: llevar asegurado por lo menos seis meses (periodo de espera); recibir la asistencia sanitaria del seguro; estar incapacitado para trabajar; y no haber provocado ni mantenido intencionalmente la enfermedad. La indemnización consistirá en el pago del cincuenta por ciento del salario. Si recibiera prestaciones a la vez de otros seguros, sociales o privados, la suma de todo lo que por ellos percibiere no deberá exceder del noventa por ciento del salario.

La indemnización se fijará para las enfermedades cuya duración mínima sea de siete días y máxima de 26 semanas. Las razones que han influido para marcar este límite mínimo de siete días son:

a) Actualmente cuando los trabajadores tienen que faltar por tan corto espacio de tiempo al trabajo no son generalmente privados del salario.

b) De todas maneras reciben asistencia sanitaria gratuita

c) El seguro no puede complicar innecesariamente el funciona- 
miento de su máquina administrativa para hacer efectivos auxilios de tan poca importancia.

En cuanto al límite máximo es también comprensible, pues si la enfermedad dura indefinidamente, el asegurado irá a caer al seguro de invalidez.

Las mujeres que dan a luz y están aseguradas en el seguro de maternidad, recibirán del seguro de enfermedad análoga protección cuando éste se comience a aplicar y absorba al primero.

$\mathrm{El}$ art. $23 \mathrm{~L}$. dispone lo relativo a la indemnización para gastos de sepelio en caso de muerte.

Los arts. 24 y 25 L. dicen que los derechos de los asegurados no pueden ser objeto de retención, cesión, embargo ni impuesto de ninguna clase. El derecho a percibir la prestación prescribe al año a partir de la fecha en que se entienda devengada.

\section{Prestaciones en especie o sanitarias:}

Son: asistencia médica, asistencia farmacéutica, hospitalización y asistencia en caso de maternidad. Por prescripción facultativa se pueden alcanzar también los servicios de prótesis, baños y ortopedia.

Asistencia médica: debe prestarse por médicos titulados y comenzará, si fuera necesario, desde el mismo día de la afiliación, pues en este seguro no se cree conveniente aplicar el periodo de carencia en cuanto a la duración de esta asistencia el artículo le fija un límite de 26 semanas; si la enfermedad no estuviera curada aún en esa fecha, su cuidado pasará a otro seguro (invalidez, por ejemplo).

Asistencia farmacéutica: es complementaria de la médica y por ende está regulada por disposiciones análogas.

Hospitalización: es una prestación de gran importancia admitida hoy en dia en todos los países. El asegurado, en general, es libre de acep) tarla o nó, pero si sufre de enfermedad contagiosa, por ej. deberá aceptarla forzosamente. Esta prestación tiende a anular la indemnización (prestación económica), pero si el asegurado tiene familia la indemnización será solamente reducida y de acuerdo con ésta. El seguro prestará este servicio por un espacio de tiempo limitado prudencialmente en doce semanas para los asegurados $\mathrm{y}$ en seis para sus familiares beneficiarios.

Asistencia de maternidad: comprende la asistencia facultativa para los periodos de gestación, puerperio y parto, asi como la utilización gratuita de las Obras de Protección a la Infancia y a la Maternidad.

Acción preventiva: como hemos dicho antes, esta acción representa para el seguro, una de las armas más eficaces para la lucha contra la enfermedad. No basta con curar al enfermo, hay que impedir que la enfermedad se reproduzca y propague, y esto es lo que los Estados modernos están tratando de conseguir al desarrollar una intensa política de sanidad general que mejore y defienda a la salud pública. El seguro pues, al emprender su acción preventiva, deberá ajustarse a las normas que le señale la Dirección General de Sanidad. 


\section{D) Recursos económicos y régimen financiero:}

Los recursos para este seguro proceden de tres fuentes principales: el Estado, el patrono y el asegurado.

El Estado: a pesar de que es muy discutible la intervención del Estado en la formación de los recursos de este seguro, en España el Estado es considerado como fuente principal, pero no cotizando sino aligerando los gastos de administración de la institución y facilitando la actuación del mismo mediante la cooperación de las instituciones que le son propias.

Primas de los trabajadores y de sus patronos:

Se presentan dos casos: obrero que trabaja por cuenta ajena y trabajador independiente.

En el primer caso la cuota será proporcional al salario que percibe el obrero. El patrono descontará del salario del obrero la parte que a éste le tocaba abonar. 'De esta manera el asegurado queda enteramente libre de gestión con la institución aseguradora y es el patrono en cambio el responsable del seguro de sus empleados.

En el segundo caso está claro que será el propio trabajador el que por medio de los sindicatos deberá abonar su cuota.

Régimen financiero: el régimen empleado es el de reparto (como en todos los países) combinado con la existencia de fondos de reserva. La ley dispone que las inversiones realizadas con los fondos deberán quedar fácilmente liquidables.

\section{E) Gestión :}

En ella hay que distinguir la función puramente administrativa y económica de la técnica sanitaria.

La función administrativa (art. 26) se encomienda a una institución que es oficial por su origen, territorial en cuanto a su administración y autónoma en la manera de desarrollar su actuación: el Instituto Nacional de Previsión.

La función técnica sanitaria estará organizada por el propio organismo asegurador que es el Instituto Nacional de Previsión; estaría prestada por el servicio médico (integrado por facultativos que hayan sido aprobados por concurso ante un jurado especial), remunerado de acuerdo con el número de familias a que preste asistencia.

En cuanto al servicio farmacéutico la ley dice que será objeto de un concierto entre el Instituto Nacional de Previsión y el Consejo General de los Colegios Farmacéuticos. Las farmacias encargadas de este servicio operarán con tarifas reducidas especiales para el seguro.

\section{F) Inspección y jurisdicción:}

\section{Inspección :}

1) La del Curpo de 'Inspectares Nacionales, del Trabajo, que velará por el cumplimiento de las obligaciones, de trabajadores y empresarios. sanitarios.

2) La inspección que se refiere al funcionamiento de los servicios

3) La inspección de la gestión administrativa del seguro obligatorio de enfermedad a cargo de los mismos órganos que ejercen esta función en los demás seguros sociales. 
Jutisdiccíón: Los magistrados del Trabajo serán los jueces competentes en las cuestiones de carácter contencioso que se susciten a propósito del seguro.

La Dirección General de Previsión también serả competente en los casos de efectividad y aplicación de las prestaciones sanitarias en su aspecto técnico-facultativo.

\section{CAPITULO VIII}

\section{UNIFICACION DE LOS SEGUROS SOCIALES.}

(Seguro total)

En los capítulos anteriores hemos estudiado el riesgo en general y los riesgos especiales con sus respectivos seguros. Fl riesgo de acridente de trabajo hizo que surgiera el Seguro de Accidentes del Trabajo, el riesgo de enfermedad trajo el seguro de enfermedad, etc...y seguirán apareciendo nuevos seguros mientras el hombre todavía esté amenazado por riesgos. Desgraciadamente no ha habido una idea básica uniforme para todos los seguros, sino que estos han ido apareciendo cuando las circunstancias los hacían indispensables con su fisonomía y reglamentación propios y es asî que presentan en primer lugar una disgregación funcional (debido a la libre elección del órgano asegurador), en segundo lugar una disgregación profesional ( pues siguen existiendo entidades aseguradoras privadas) y en tercer lugar una disgregación territorial (debido a la existencia de cajas territoriales autónomas del Estado e independientes entre sí). Lo ideal sería entonces organizar un nuevo seguro total, unificador, que cubriera todos los riesgos posibles.

Soluciones doctrinales: hay tres opiniones muy marcadas sobre este punto de la unificación de los seguros sociales. Una pretende que el riesgo en cada seguro es especial, distinto de los demás, y que en consecuencia las probabilidades de su manifestación son distintas y las reparaciones que merece bien diversas en cada caso. Otros sostienen que hay un sólo riesgo, el de la falta de trabajo y que resultaría fácil hacer un sólo seguro con lo que tienen de comun los que actualmente existen. En tercer lugar tenemos la opinión intermedia, la que sostiene que no hay unidad en el riesgo pero sí cierta similitud que permitiría la coordinación de todos los seguros. Parece que esta es opinión más acertada y que mayores probabilidades de éxito tiene. Sus ventajas son de orden legal, técnico, social, administrativo etc...

Hasta la fecha los países que más cerca han llegado en lo referente a la unificación han sido Rusia, Yugoeslavia y Checoeslovaquia. El Plan Beveridge en Gran Bretaña también va a influir poderosamente en las reformas sociales de la postguerra.

En España se está estudiando, desde hace mucho tiempo, este problema y ya está preparando el Instituto Nacional de Previsión un proyecto de seguro total que esperamos ardientemente sea pronto una realidad. 